Supporting Information

Thermodynamics, Structure, and Dynamic Properties of Nanostructured Water Confined into B-, N-, and Si-Doped

\title{
Graphene Surfaces and Carbon Nanotubes
}

Mohsen Abbaspour, Hamed Akbarzadeh, and Shadi Zaeifi

Department of Chemistry, Hakim Sabzevari University, 96179-76487 Sabzevar, Iran 
Table S1. The number of water molecules at different pore widths and densities in graphene systems

\begin{tabular}{|c|c|c|}
\hline $\mathrm{d}(\AA)$ & Density & $\begin{array}{c}\text { Number of } \\
\text { water } \\
\text { molecules }\end{array}$ \\
\hline \multirow{4}{*}{6} & 0.2 & 46 \\
\cline { 2 - 3 } & 0.4 & 92 \\
\cline { 2 - 3 } & 0.6 & 138 \\
\cline { 2 - 3 } & 0.8 & 208 \\
\cline { 2 - 3 } & 1 & 230 \\
\hline \multirow{2}{*}{8} & 0.6 & 184 \\
\hline \multirow{2}{*}{10} & 0.6 & 230 \\
\hline
\end{tabular}

Table S2. The number of water molecules at different CNT systems

\begin{tabular}{|c|c|c|}
\hline CNT & Density & $\begin{array}{c}\text { Number of } \\
\text { water } \\
\text { molecules }\end{array}$ \\
\hline$(14,0)$ & 0.2 & 90 \\
\hline$(15,0)$ & 0.2 & 108 \\
\hline
\end{tabular}


Table S3. The Lennard-Jones (LJ) parameters ${ }^{58-60}$ used in this work

\begin{tabular}{ccc}
\hline Interaction & $\varepsilon(\mathrm{kJ} / \mathrm{mol})$ & $\sigma(\AA)$ \\
\hline $\mathrm{C}-\mathrm{C}$ & 0.2763 & 3.469 \\
$\mathrm{~B}-\mathrm{B}$ & 0.3971 & 3.453 \\
$\mathrm{~N}-\mathrm{N}$ & 0.6060 & 3.365 \\
$\mathrm{Si}-\mathrm{Si}$ & 1.6789 & 4.295 \\
\hline
\end{tabular}




\section{S1. Effect of the doped atom distribution}

To examine the effect of the doped atom distribution, we have distributed the doped atoms in the high (20\%) doped systems with two states: periodically and randomly. The total energy, average number of the HBs, and self-diffusion coefficient of the confined water molecules between the graphene surfaces and into the doped CNTs with the two different doped atoms distributions have been presented at $300 \mathrm{~K}$ in Tables S4 and S5 in the supporting information. The O-H radial distribution functions of the confined molecules have been also presented in Fig. S8 in the supporting information.

According to Tables S4 and S5 and also Fig. S2, there are not much differences between the results in both states. However, it is shown that these differences are very small in the total energy, average number of HBs, and the RDFs whereas they become larger in the diffusion coefficient values. To more investigate this situation, we have presented the snapshots of the confined water molecules between the doped graphene (at different densities) and into the doped CNT in both states in Fig. S3 and S4, respectively. According to these figures, there is not much differences between the two states. However, according to Fig. S3, at low density $(\rho=0.2(\mathrm{~g} / \mathrm{cc}))$ for Si-doped system, we cannot observe the three discrete water chains in the random state (which was observed in the periodic state). The formation of the discrete water chains in the periodically doped graphene is due to the response of water molecules to the attraction of the periodic Si-doped atoms. By careful observation to Fig. S3 we can find that the confined water molecules create more ordered shapes in the randomly distributed doped atoms at higher density $(\rho=1(\mathrm{~g} / \mathrm{cc}))$ in both $\mathrm{N}$ - and Si-doped systems. This result is in agreement with the higher $<\mathrm{HB}>$ and smaller diffusion coefficient of confined water molecules in the randomly distributed doped atoms in the graphene system. However, according to Fig. $\mathrm{S} 4$, the confined water molecules into the periodically distributed doped atoms in the $(14,0)$ CNT create more ordered pentagonal shape than the randomly distributed CNT. The $<\mathrm{HB}>$ of the confined water molecules is also greater for the random doped atoms distribution in $(14,0)$ CNT. 
Table S4. The total energy, average number of the HBs, and self-diffusion coefficient of the confined water molecules between the graphene surfaces with the two different doped atoms distributions.

Property Periodic Completely random

\section{Total energy $(\mathrm{kJ} / \mathrm{mol})$}

$\begin{array}{lrr}(20 \%) \text { B-doped, } \rho=0.2(\mathrm{~g} / \mathrm{cc}) & -34.5609 & -34.8978 \\ (20 \%) \text { B-doped, } \rho=0.6(\mathrm{~g} / \mathrm{cc}) & -42.1862 & -42.3565 \\ (20 \%) \text { B-doped, } \rho=1(\mathrm{~g} / \mathrm{cc}) & 37.4004 & 40.3969 \\ (20 \%) \text { N-doped, } \rho=0.2(\mathrm{~g} / \mathrm{cc}) & -36.4696 & -34.6152 \\ (20 \%) \text { N-doped, } \rho=0.6(\mathrm{~g} / \mathrm{cc}) & -43.2319 & -42.4623 \\ (20 \%) \text { N-doped, } \rho=1(\mathrm{~g} / \mathrm{cc}) & 37.3900 & 39.4956 \\ (20 \%) \text { Si-doped, } \rho=0.2(\mathrm{~g} / \mathrm{cc}) & -33.1217 & -31.2261 \\ (20 \%) \text { Si-doped, } \rho=0.6(\mathrm{~g} / \mathrm{cc}) & -36.4507 & -33.9471 \\ (20 \%) \text { Si-doped, } \rho=1(\mathrm{~g} / \mathrm{cc}) & 78.9130 & 82.6609\end{array}$

\section{Average number of $\mathrm{HBs}$}

(20\%) B-doped, $\rho=0.2(\mathrm{~g} / \mathrm{cc})$

(20\%) B-doped, $\rho=0.6(\mathrm{~g} / \mathrm{cc})$

(20\%) N-doped, $\rho=0.2(\mathrm{~g} / \mathrm{cc})$

(20\%) Si-doped, $\rho=0.2$ (g/cc)

0.63

(20\%) Si-doped, $\rho=0.6$ (g/cc)

1.54

1.60

(20\%) Si-doped, $\rho=1$ (g/cc)

4.90

\section{Self-Diffusion $\left(10^{-10} \mathrm{~m}^{2} / \mathrm{s}\right)$}

(20\%) B-doped, $\rho=0.2(\mathrm{~g} / \mathrm{cc})$

(20\%) B-doped, $\rho=0.6(\mathrm{~g} / \mathrm{cc})$

(20\%) B-doped, $\rho=1(\mathrm{~g} / \mathrm{cc})$

$2.0367 \times 10^{-3}$

$1.6642 \times 10^{-3}$

$(20 \%) \mathrm{N}$-doped, $\rho=0.2(\mathrm{~g} / \mathrm{cc})$ 


$\begin{array}{lll}(20 \%) \text { N-doped, } \rho=0.6(\mathrm{~g} / \mathrm{cc}) & 0.1270 & 0.08969 \\ (20 \%) \text { N-doped, } \rho=1(\mathrm{~g} / \mathrm{cc}) & 3.1050 \times 10^{-3} & 1.2787 \times 10^{-3} \\ (20 \%) \text { Si-doped, } \rho=0.2(\mathrm{~g} / \mathrm{cc}) & 0.0868 & 0.04543 \\ (20 \%) \text { Si-doped, } \rho=0.6(\mathrm{~g} / \mathrm{cc}) & 5.8850 \times 10^{-3} & 4.5267 \times 10^{-3} \\ (20 \%) \text { Si-doped, } \rho=1(\mathrm{~g} / \mathrm{cc}) & 2.3683 \times 10^{-3} & 2.0700 \times 10^{-3}\end{array}$

Table S5. The total energy and average number of the HBs of the confined water molecules into the $(14,0)$ CNT with the two different doped atoms distributions.

\begin{tabular}{lcr}
\hline Property & Periodic & Completely random \\
\hline Total energy (kJ/mol) & & \\
$(20 \%)$ N-doped & -53.5644 & -53.2744 \\
Average number of HBs & & 1.82 \\
$(20 \%)$ N-doped & 1.92 & \\
\hline
\end{tabular}


Table S6. The total energy, average number of the HBs, and self-diffusion coefficient of the confined water molecules between the graphene surfaces with the random doped atoms distributions at the different pore widths.

Property $\quad \mathrm{d}=6 \AA \quad \mathrm{d}=8 \AA \quad \mathrm{d}=10 \AA$

\section{Total energy (kJ/mol)}

$(20 \%)$ N-doped, $\rho=0.6(\mathrm{~g} / \mathrm{cc}) \quad-42.4623 \quad-44.1440 \quad-41.3461$

\section{Average number of $\mathrm{HBs}$}

\begin{tabular}{|c|c|}
\hline$(20 \%) \mathrm{N}$-doped, $\rho=0.6(\mathrm{~g} / \mathrm{cc})$ & 1.69 \\
\hline
\end{tabular}

Self-Diffusion $\left(10^{-10} \mathrm{~m}^{2} / \mathrm{s}\right)$

\begin{tabular}{|c|c|}
\hline$(20 \%) \mathrm{N}$-doped, $\rho=0.6(\mathrm{~g} / \mathrm{cc})$ & 0.08969 \\
\hline
\end{tabular}

Table S7. The total energy and average number of the HBs of the confined water molecules into the different CNTs with the random doped atoms distributions.

Property $\quad(14,0) \mathrm{CNT} \quad(15,0) \mathrm{CNT}$

\section{Total energy (kJ/mol)}

$(20 \%)$ N-doped

$-53.2744$

$-52.1898$

\section{Average number of $\mathrm{HBs}$}

(20\%) N-doped 
Table S8. The total energy, average number of the HBs, and self-diffusion coefficient of the confined water molecules between the graphene surfaces with the random doped atoms distribution at the pore width of $6(\AA)$ at different temperatures.

\begin{tabular}{lllll}
\hline Property & $300 \mathrm{~K}$ & $400 \mathrm{~K}$ & $500 \mathrm{~K}$ & $600 \mathrm{~K}$ \\
\hline
\end{tabular}

Total energy (kJ/mol)

$(20 \%)$ N-doped, $\rho=0.6(\mathrm{~g} / \mathrm{cc}) \quad-42.4623 \quad-34.2420 \quad-27.4638 \quad-21.9341$

\section{Average number of $\mathrm{HBs}$}

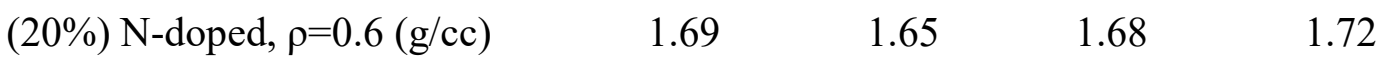

Self-Diffusion $\left(10^{-10} \mathrm{~m}^{2} / \mathrm{s}\right)$

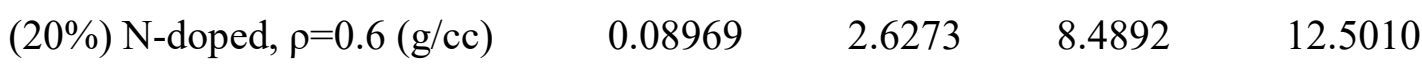

Table S9. The total energy and average number of the HBs of the confined water molecules into $(14,0)$ CNT with the random doped atoms distribution at different temperatures.

\begin{tabular}{lllll}
\hline Property & $300 \mathrm{~K}$ & $400 \mathrm{~K}$ & $500 \mathrm{~K}$ & $600 \mathrm{~K}$ \\
\hline
\end{tabular}

\section{Total energy (kJ/mol)}

$\begin{array}{lllll}(20 \%) \mathrm{N} \text {-doped } & -53.2744 & -47.2033 & -44.7744 & -25.8500\end{array}$

\section{Average number of HBs}

$\begin{array}{lllll}(20 \%) \mathrm{N} \text {-doped } & 1.82 & 1.90 & 1.88 & 1.80\end{array}$



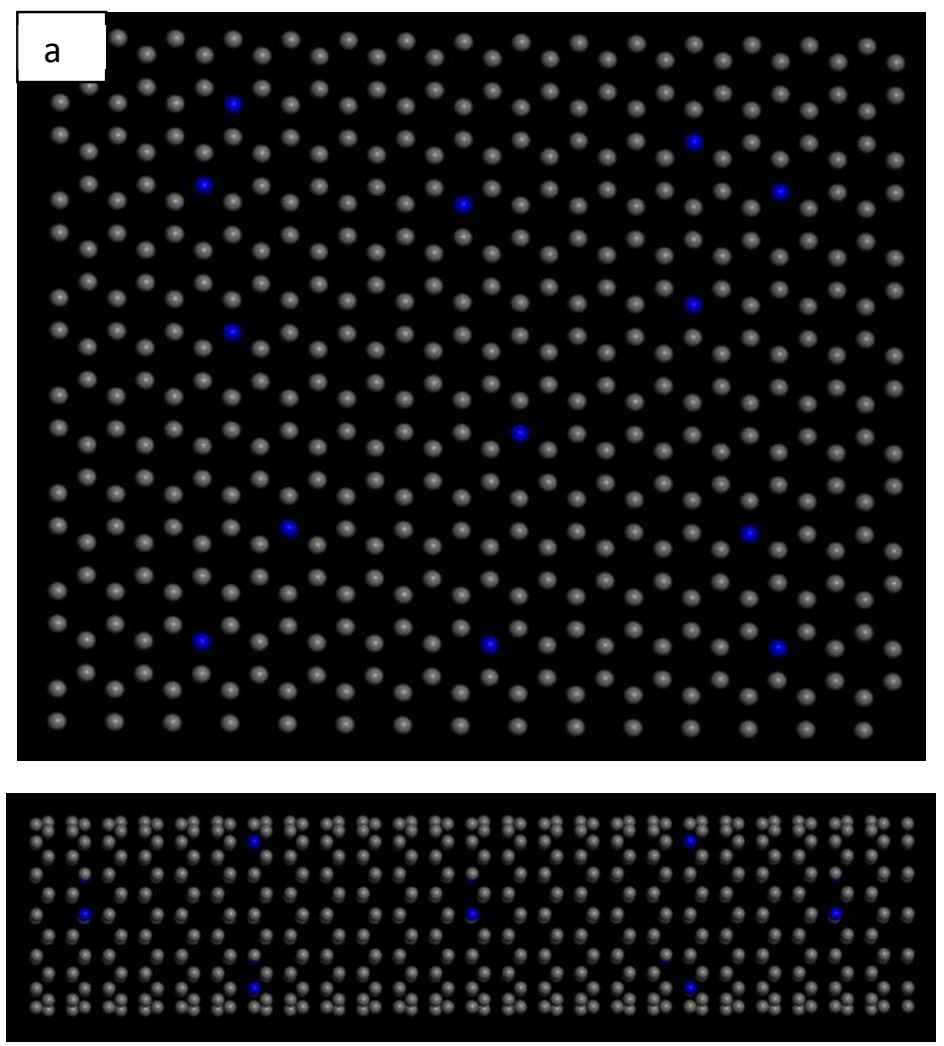

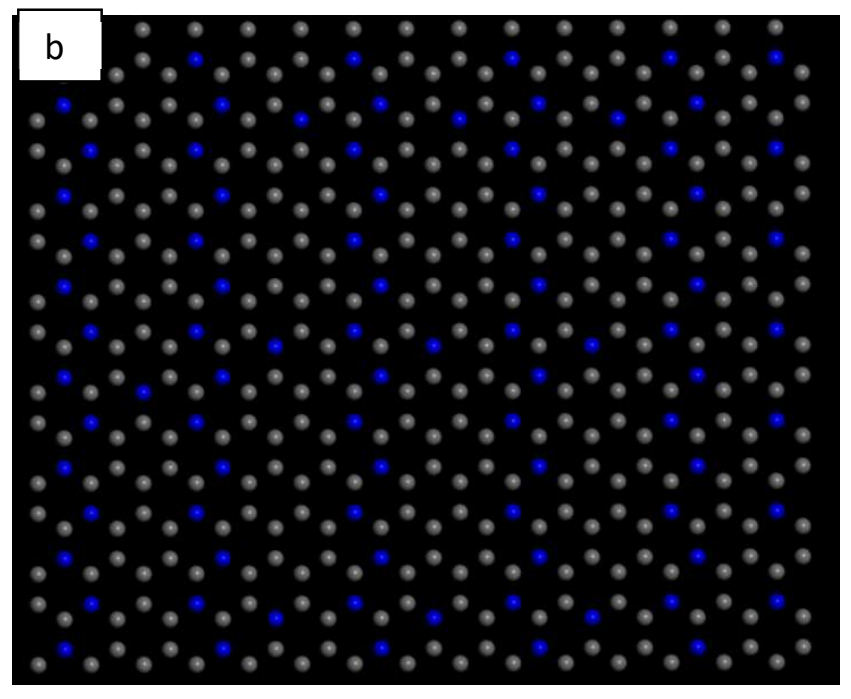

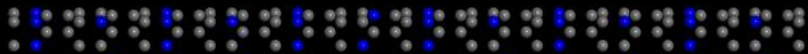

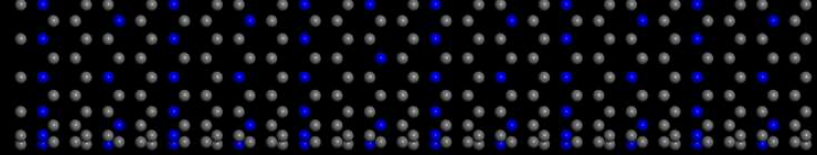

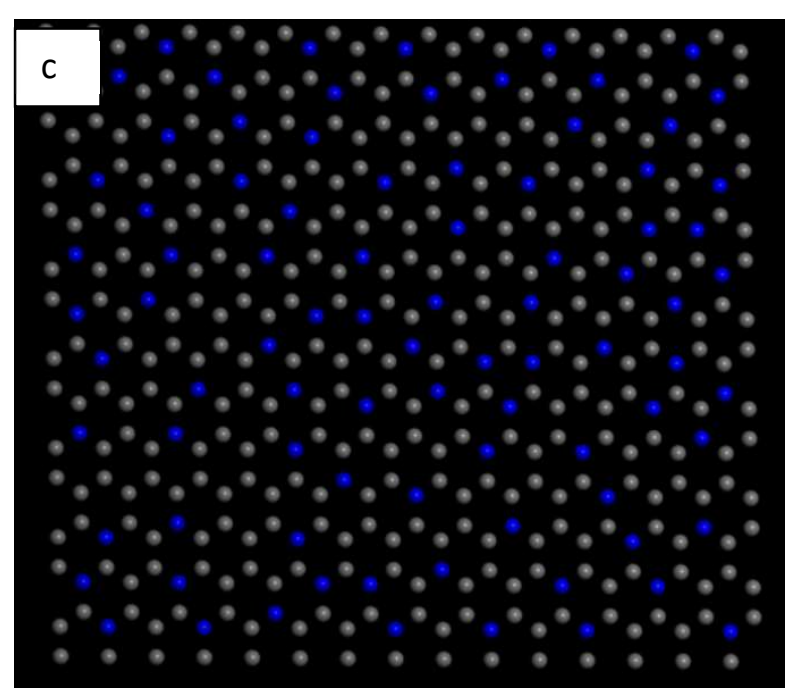

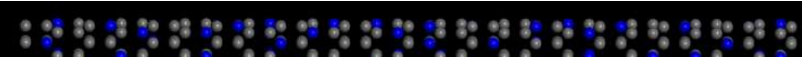

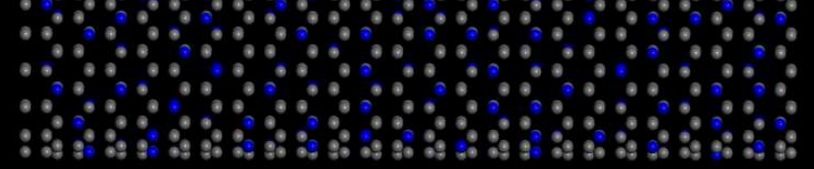

Fig. S1. The snapshots of the a) low (3\%) doped graphene and CNT systems with random distribution and the b) high (20\%) doped graphene and CNT systems with periodic and c) distributions. The carbon and doped atoms are in gray and blue, respectively. 

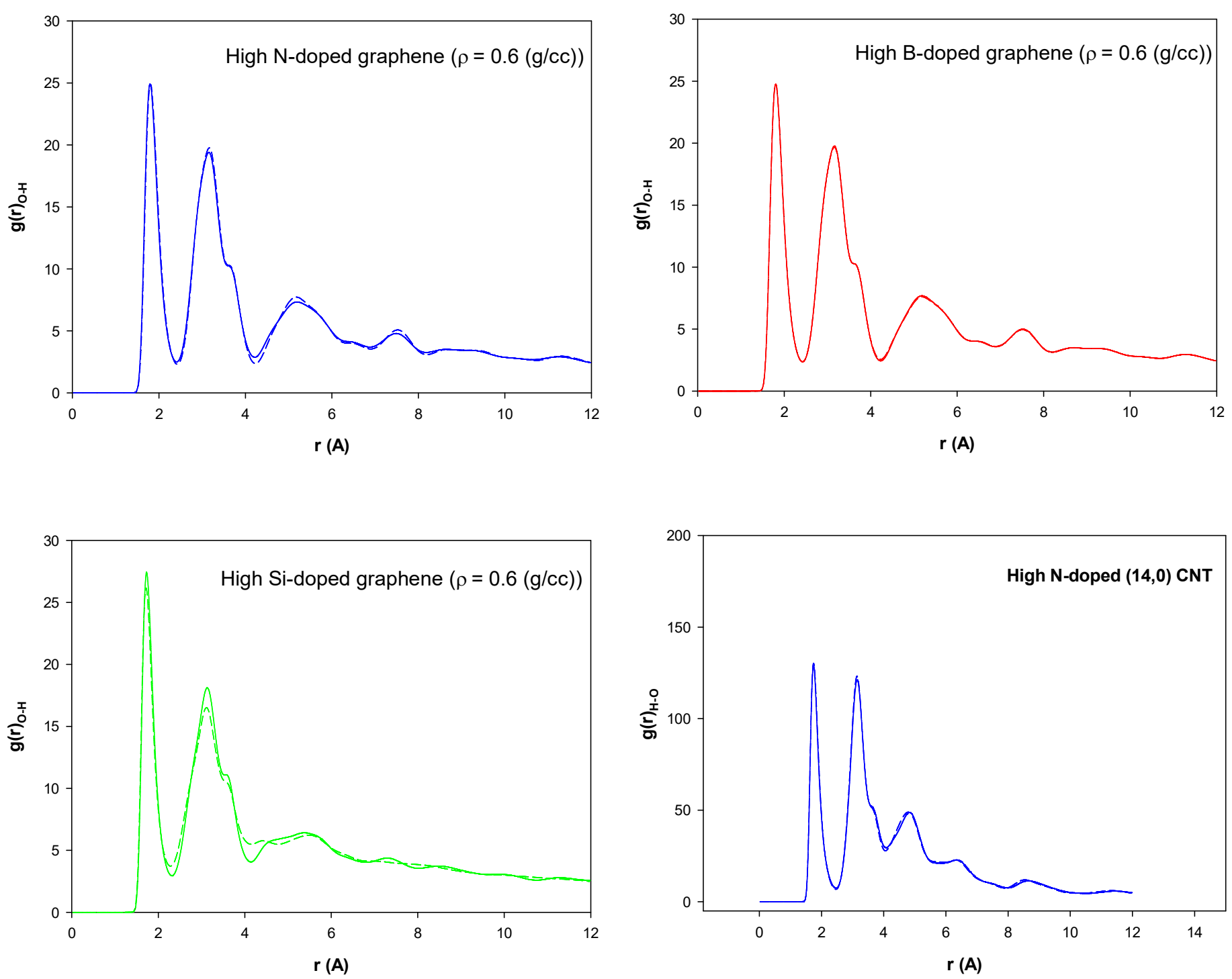

Fig. S2. The O-H RDFs of the confined molecules in the high doped systems with the two different doped atoms distributions: periodically (solid lines) and randomly (dashed lines). 


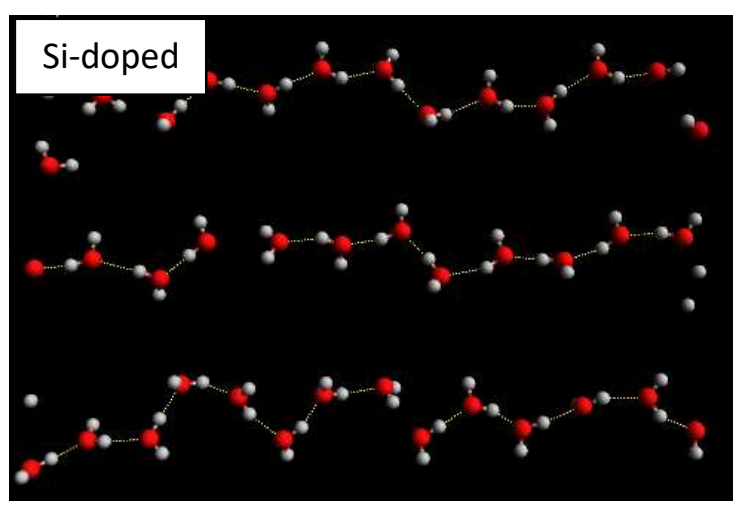

$\rho=0.2(\mathrm{~g} / \mathrm{cc})$

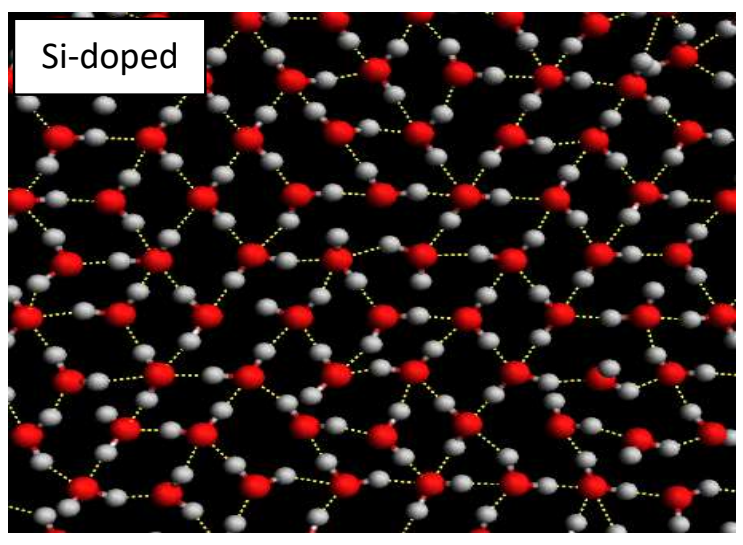

$\rho=1(g / c c)$

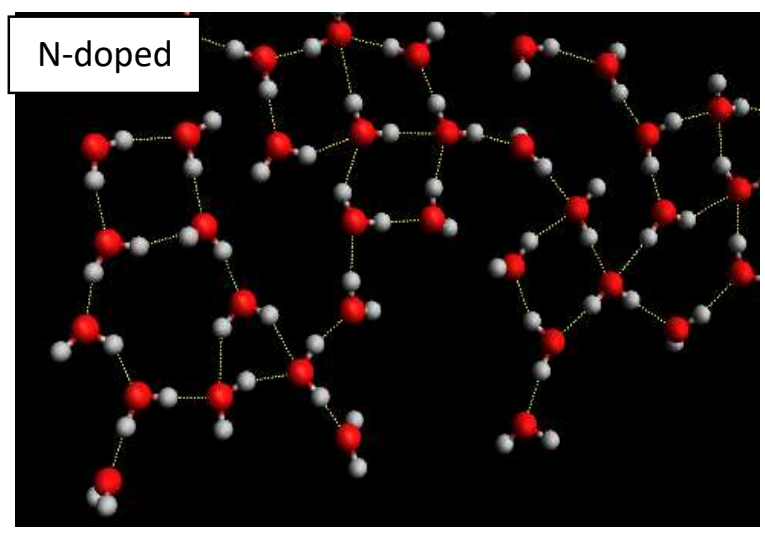

$\rho=0.2(\mathrm{~g} / \mathrm{cc})$
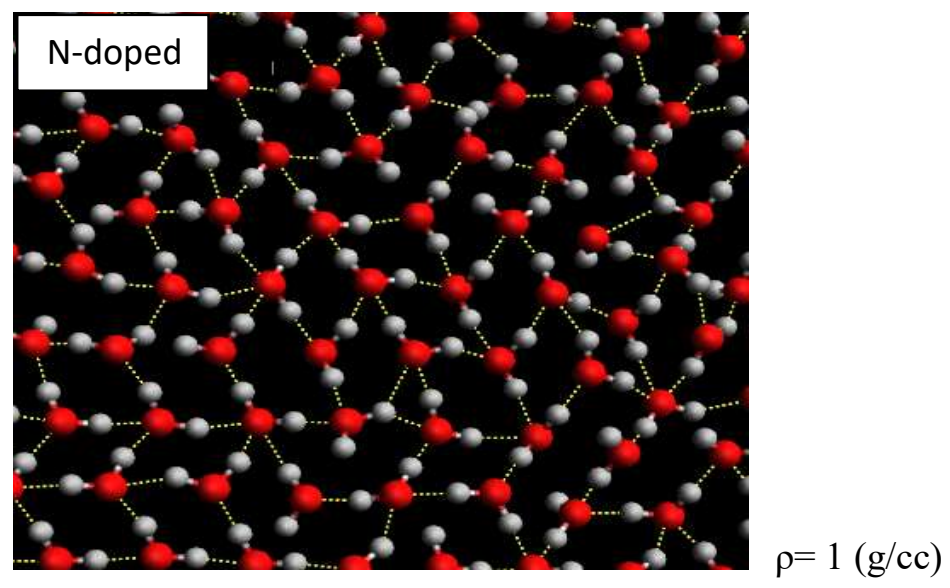
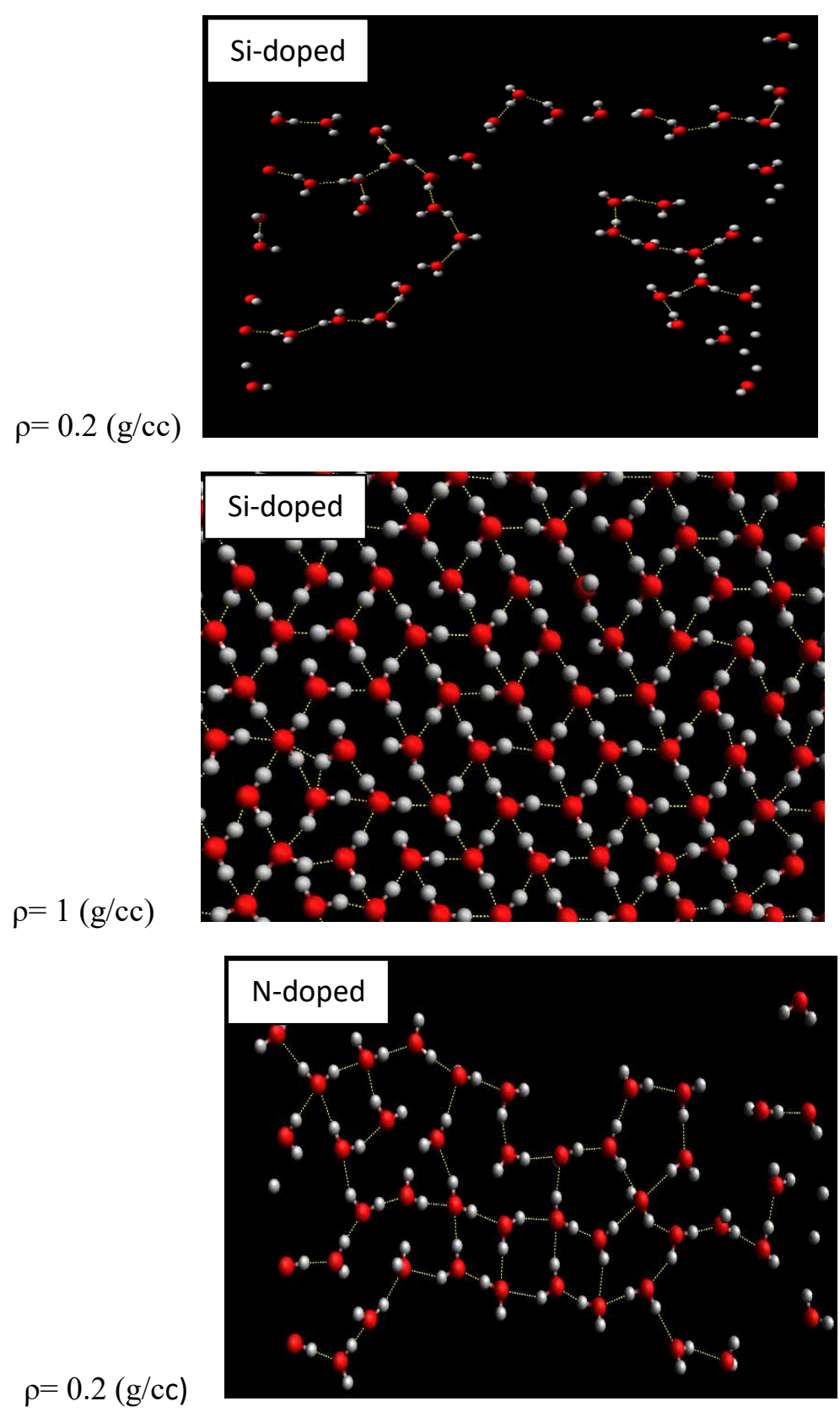

Fig. S3. The snapshots of the confined water molecules between in the high doped graphene at different densities with the two different doped atoms distributions: periodically (left side) and randomly (right side). 

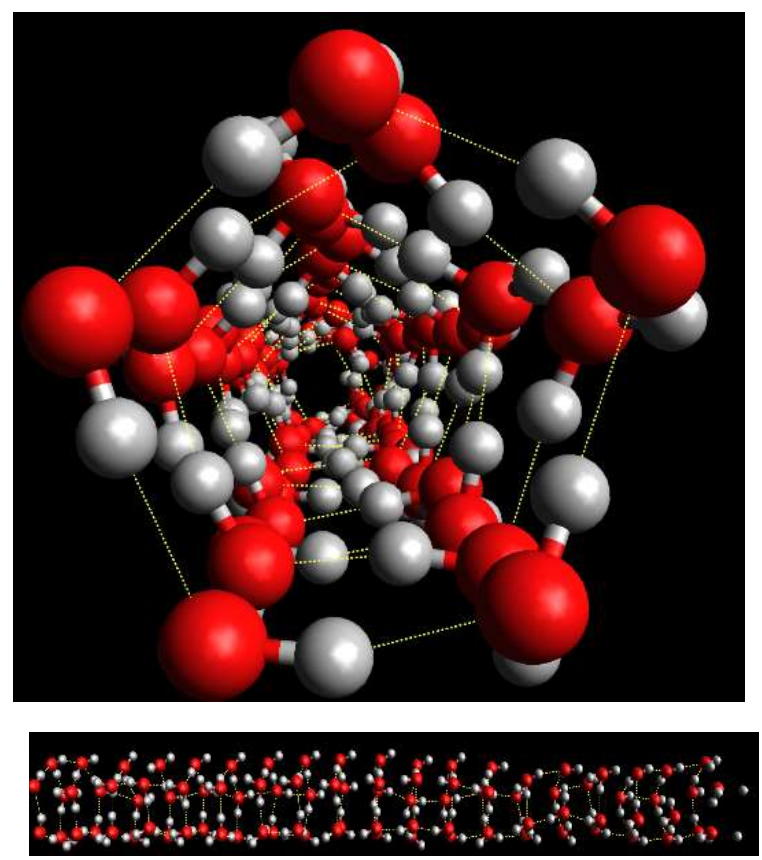
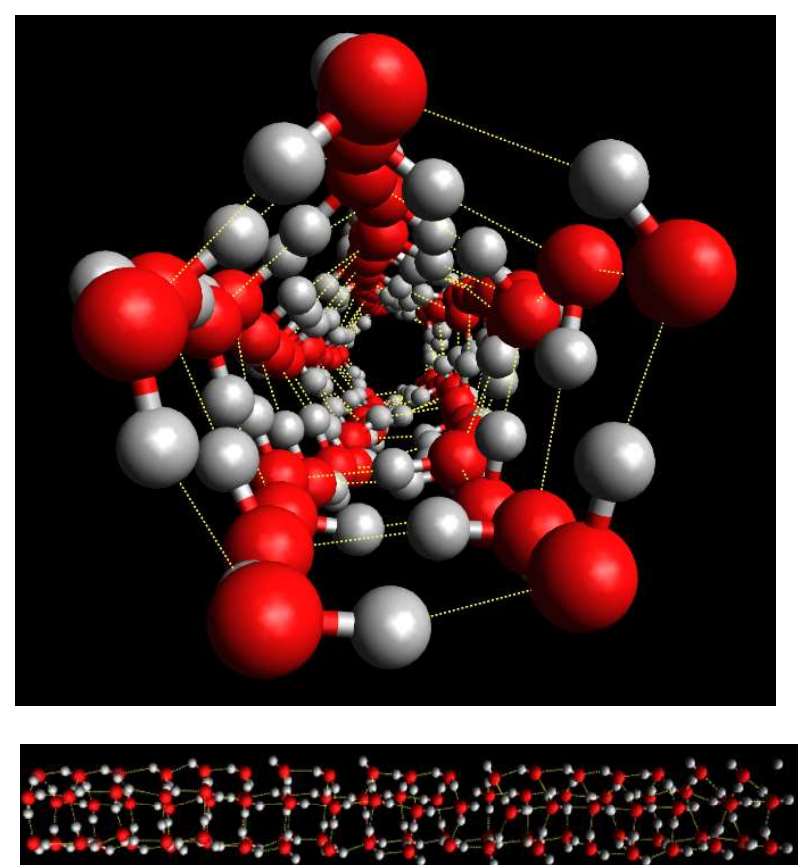

Fig. S4. The snapshots of the confined water molecules into the high N-doped $(14,0)$ CNT with the two different doped atoms distributions: periodically (left side) and randomly (right side). 

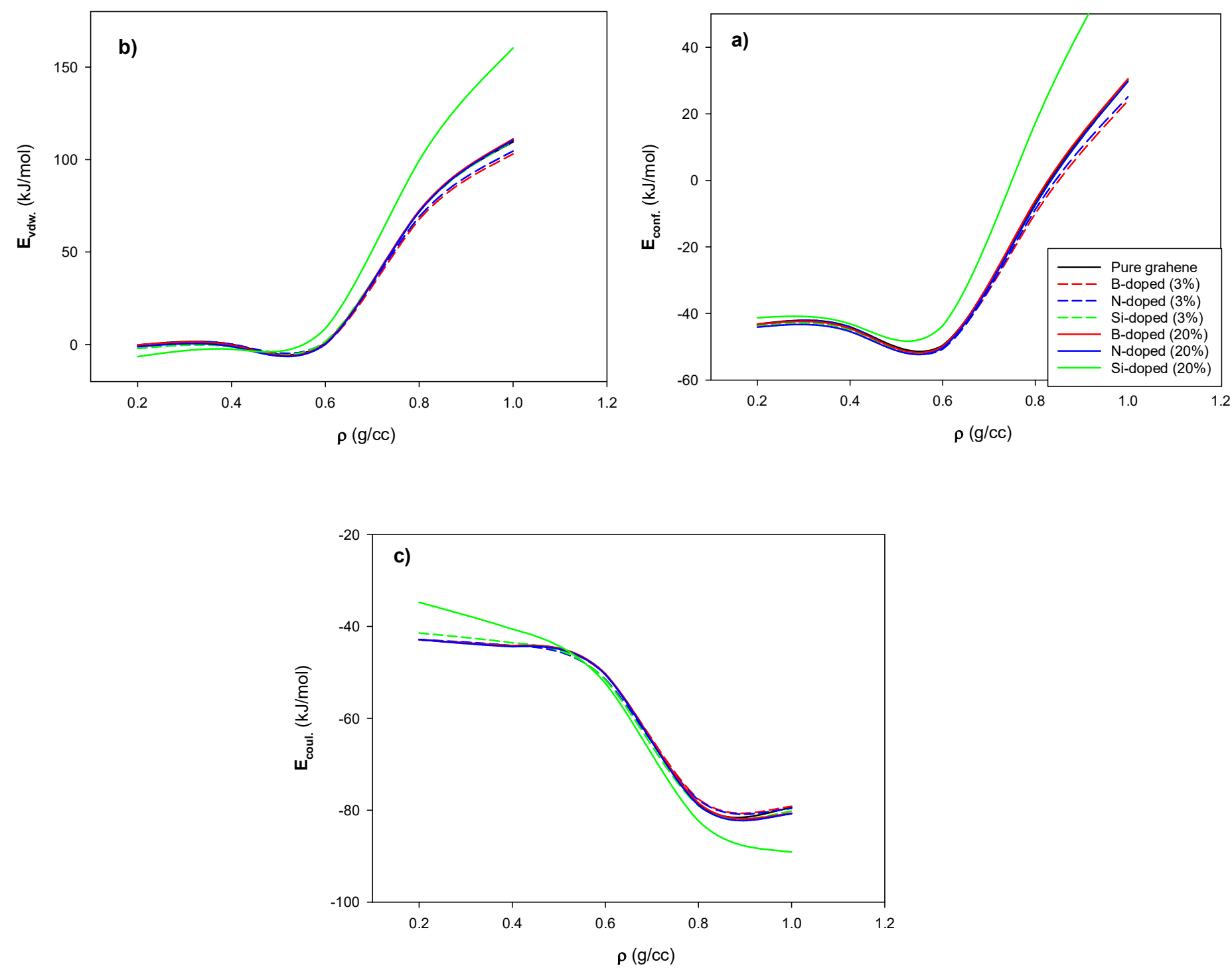

Fig. S5. The smoothed a) configurational, b) van der Waals, and c) columbic energy curves (per molecule) of confined water molecules with the different densities in the pure and the different doped systems. 


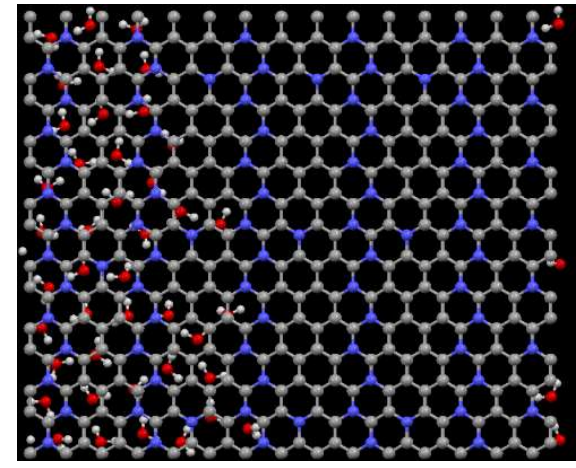

$\rho=0.2(\mathrm{~g} / \mathrm{cc})$

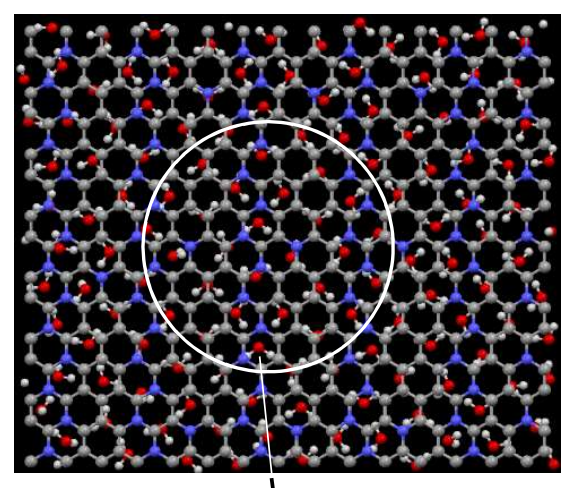

$\rho=0.6(\mathrm{~g} / \mathrm{c})$

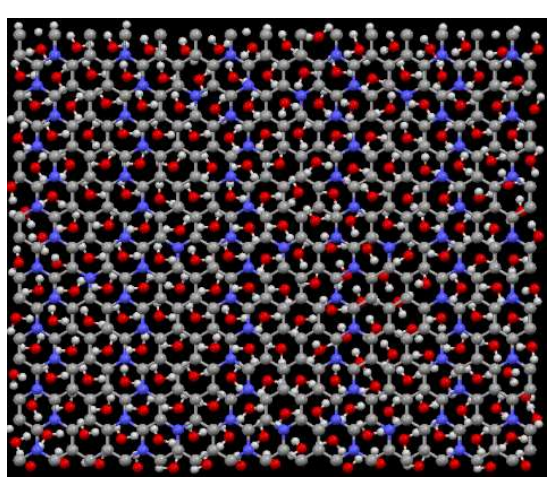

$\rho=1(\mathrm{~g} / \mathrm{cc})$

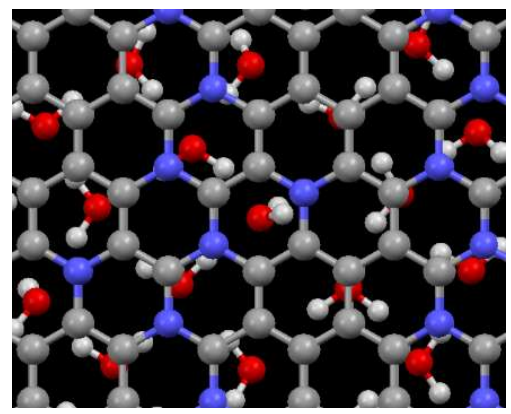

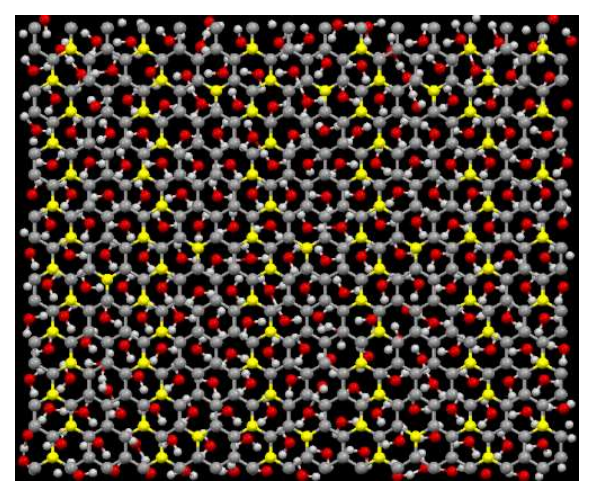

$\rho=0.2(\mathrm{~g} / \mathrm{cc})$

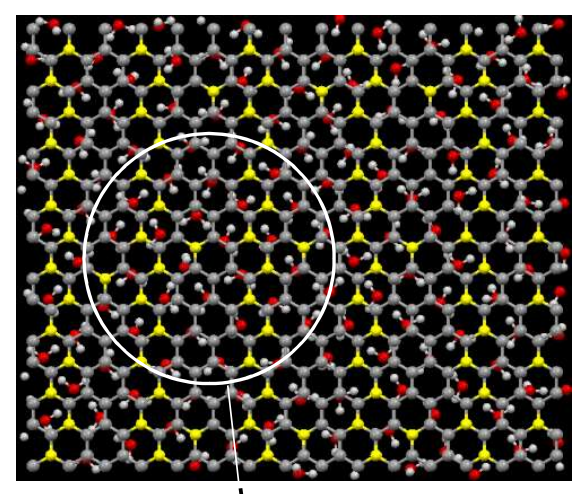

$\rho=0.6(\mathrm{~g} / \mathrm{cc})$

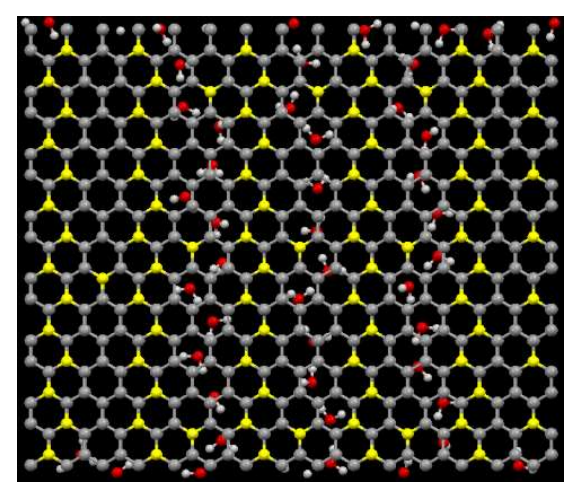

$\rho=1(\mathrm{~g} / \mathrm{cc})$

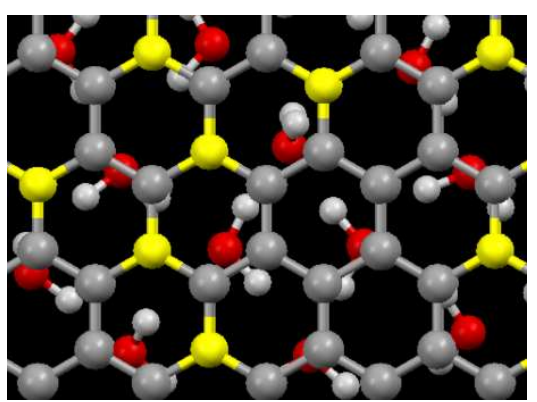

Fig. S6. The snapshots of the 20\% N-doped (above) and 20\% Si-doped (below) systems at the different densities. The carbon atoms are in gray, nitrogen atoms in blue, silicon atoms in yellow, oxygen atoms in red, and hydrogen atoms in silver. 

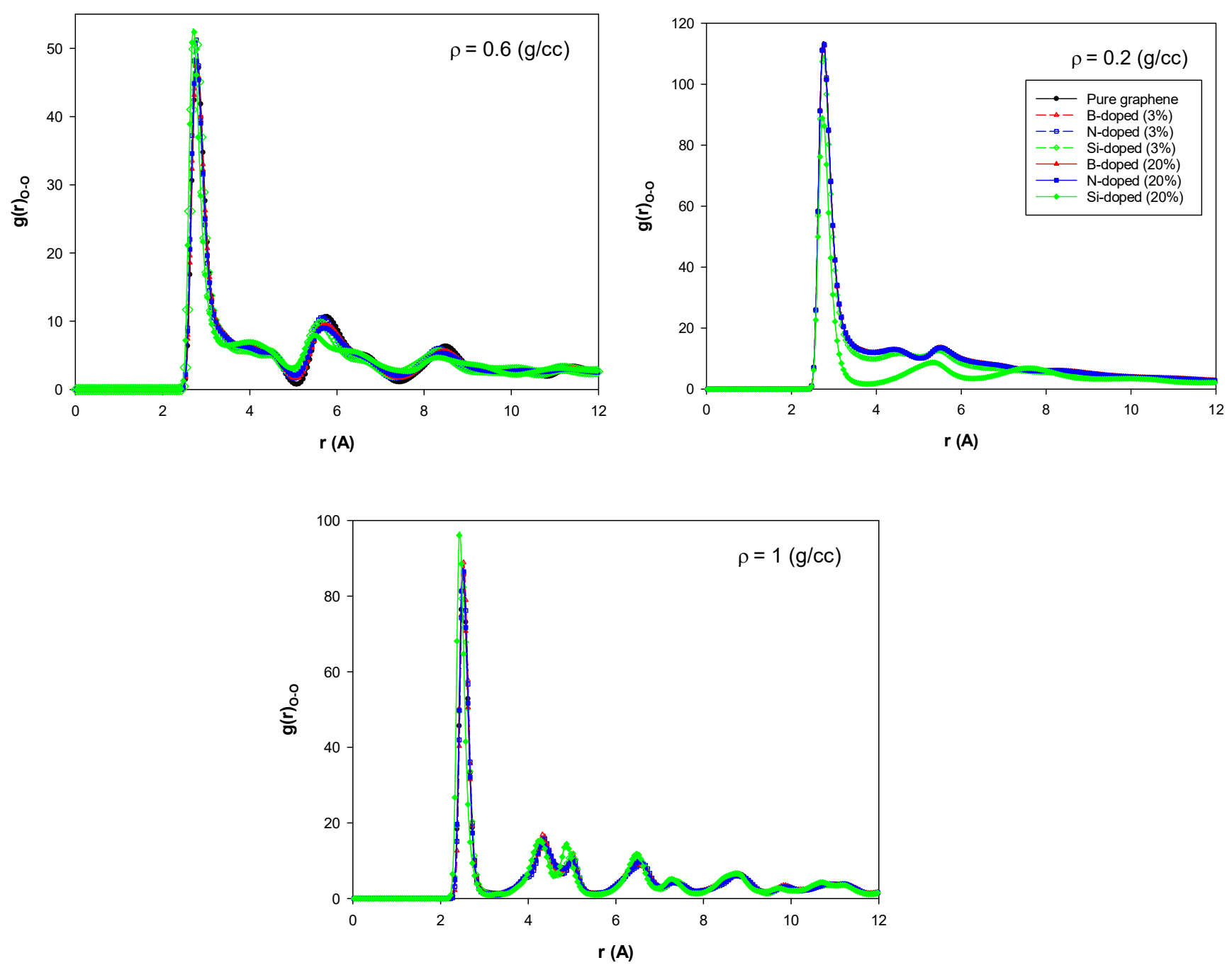

Fig. S7. The O-O RDF of the confined water molecules in the pure and the different doped systems at the different densities. 

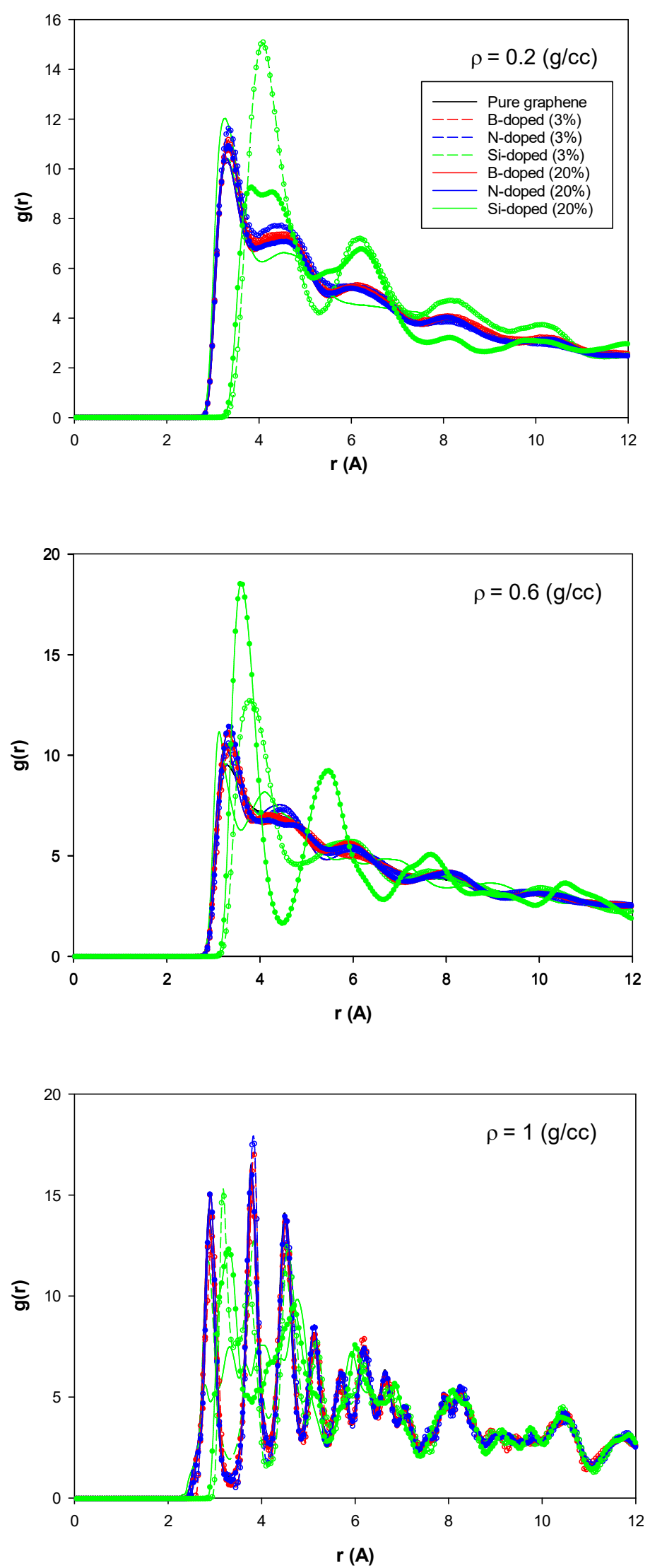

Fig. S8. The C-O RDFs (lines without symbols) and doped atom-O RDFs (lines with symbols) in the pure and the different doped systems at the different densities. 

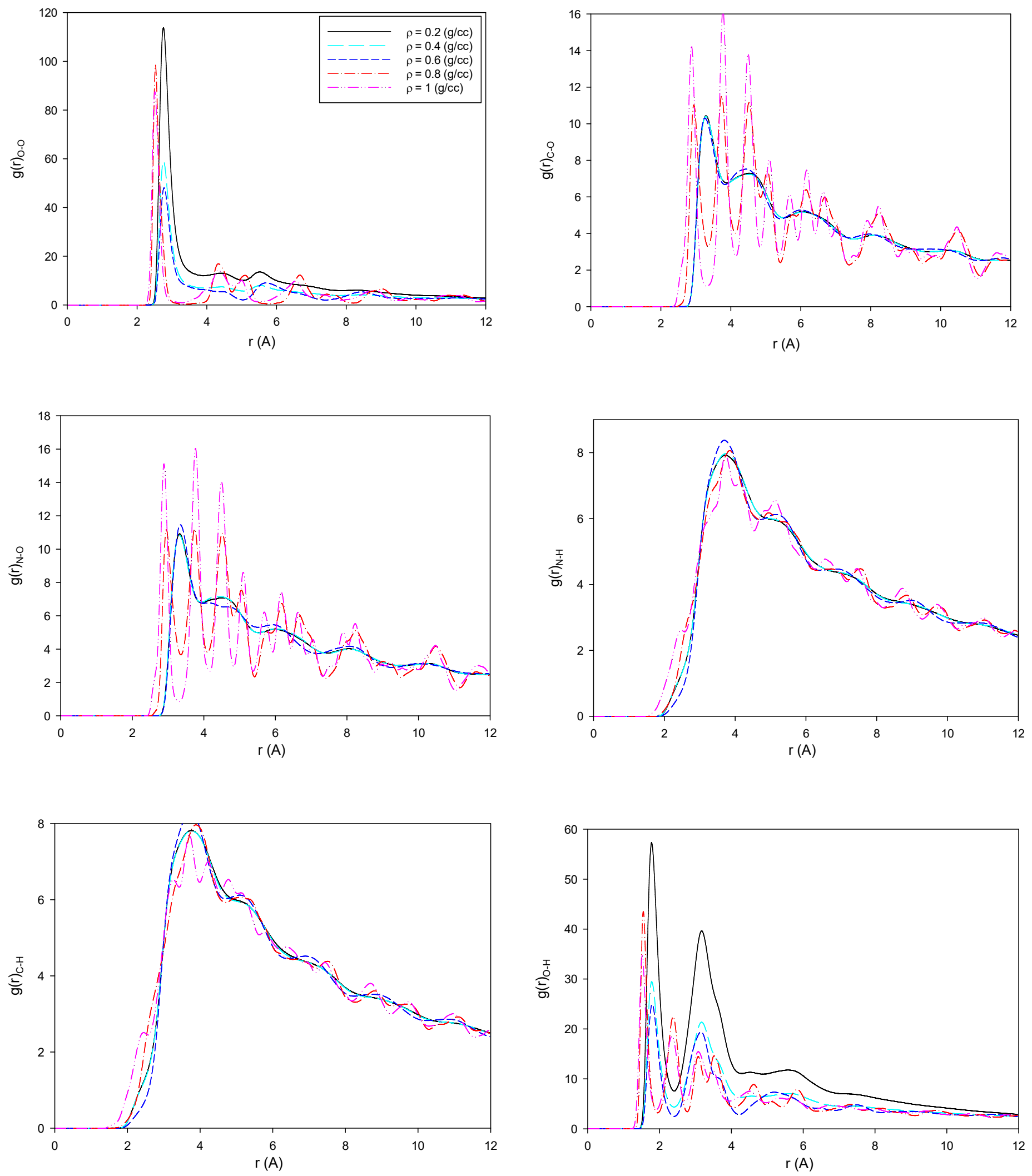

Fig. S9. The different RDFs of the confined water molecules in the high N-doped system at the different densities. 


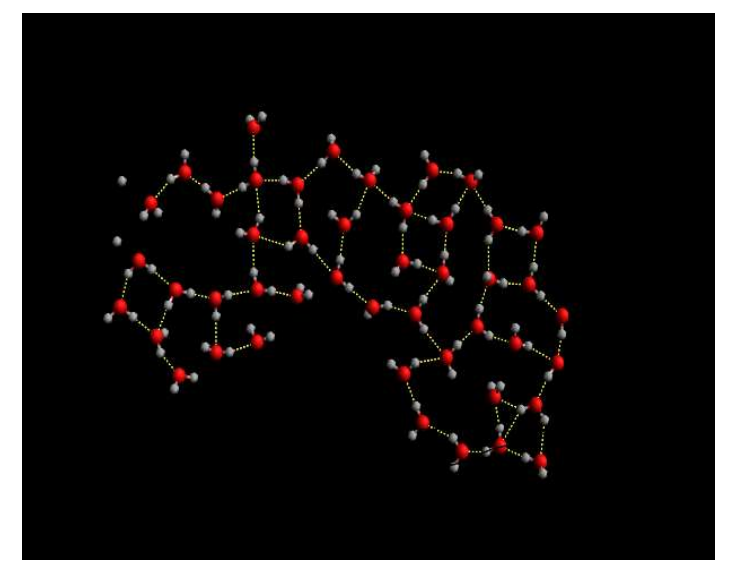

$\rho=0.2(g / c c)$

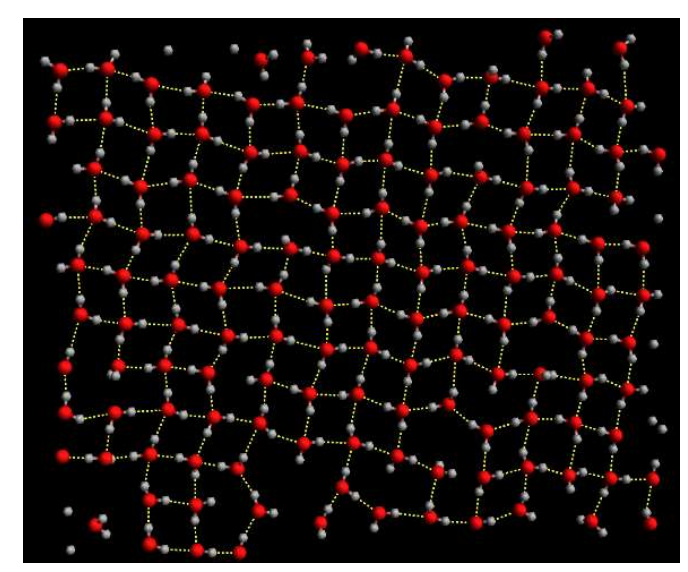

$\rho=0.6$ (g/cc)

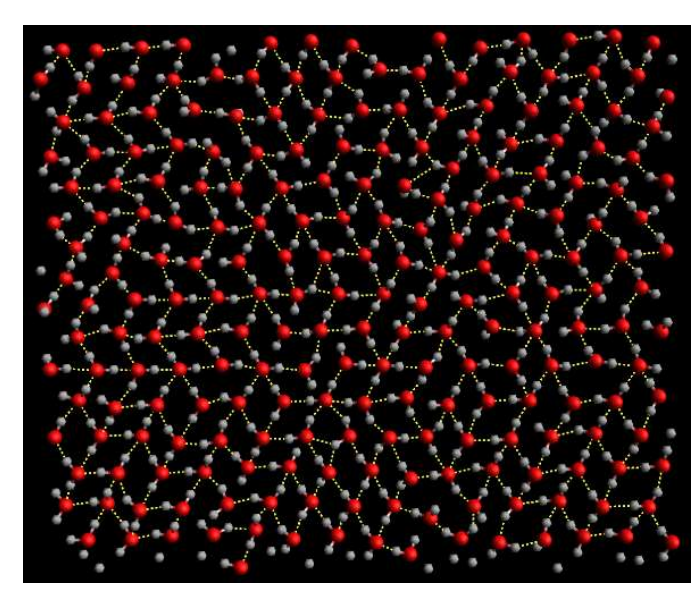

$\rho=1(g / c c)$

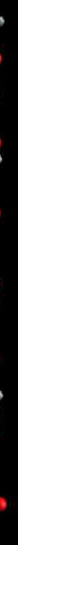

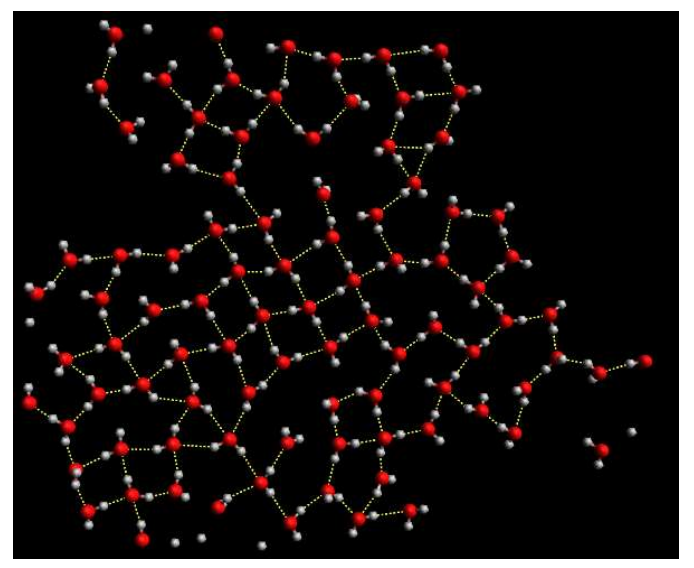

$\rho=0.4(g / c c)$

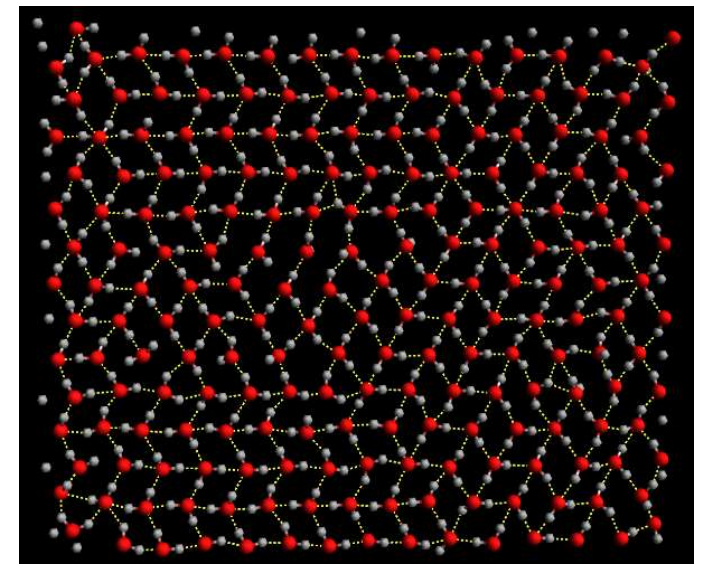

$\rho=0.8(g / c c)$

$$
\text { c) }
$$



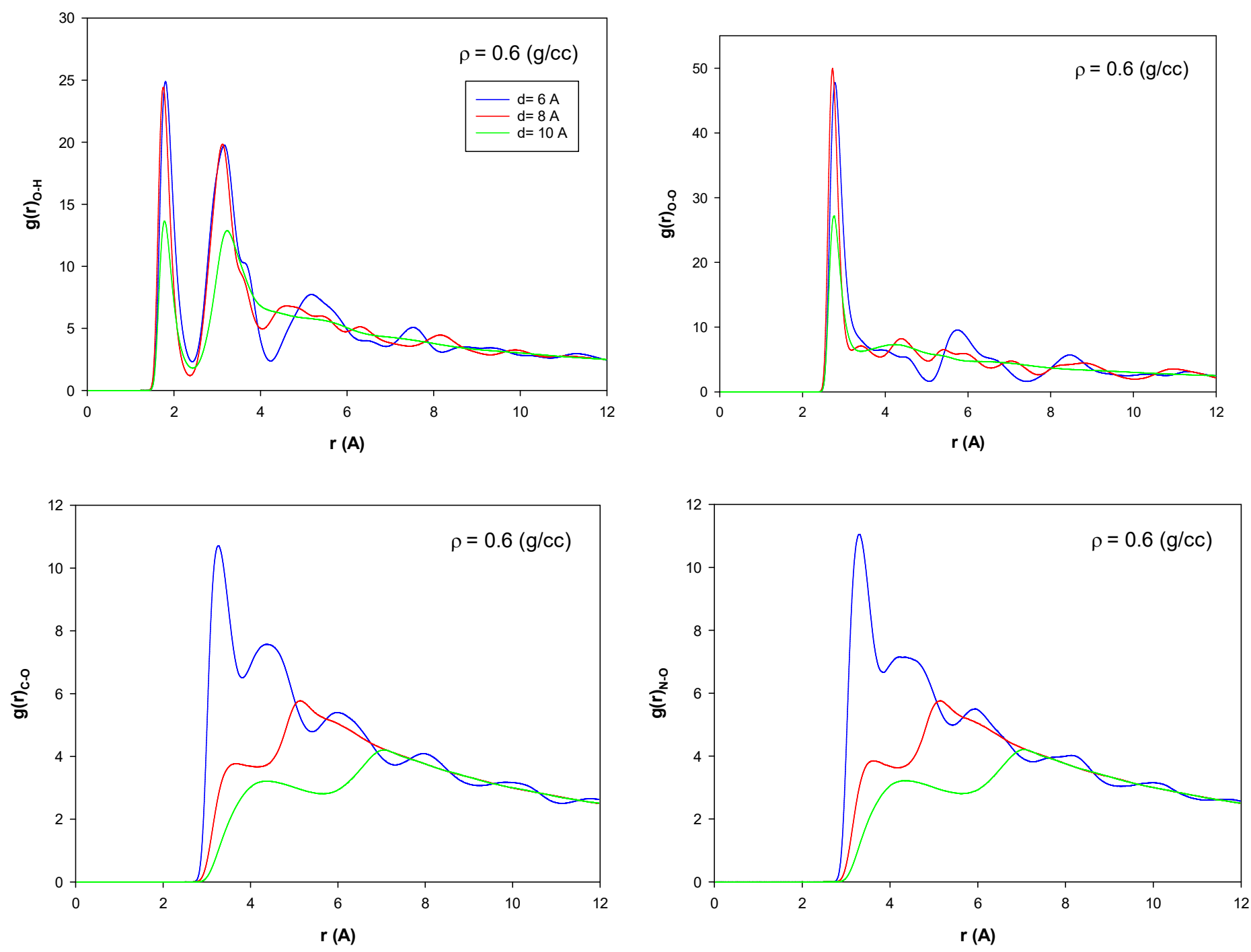

Fig. S11. The different RDFs of the confined molecules in the high N-doped graphene with the random doped atoms distribution at different slit pore sizes. 

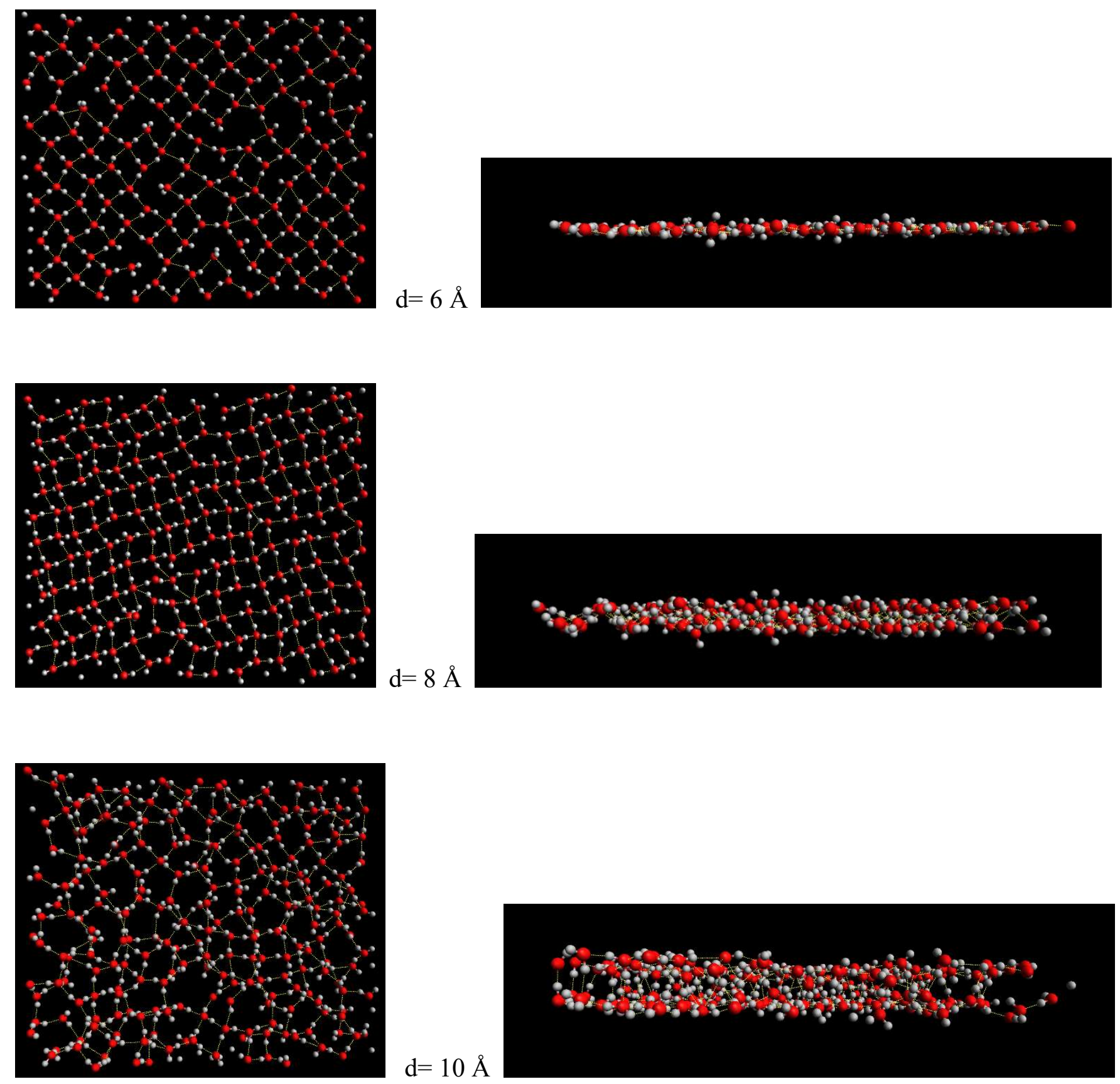

Fig. S12. The snapshots of the confined molecules in the high N-doped graphene with the random doped atoms distribution at different slit pore sizes. 

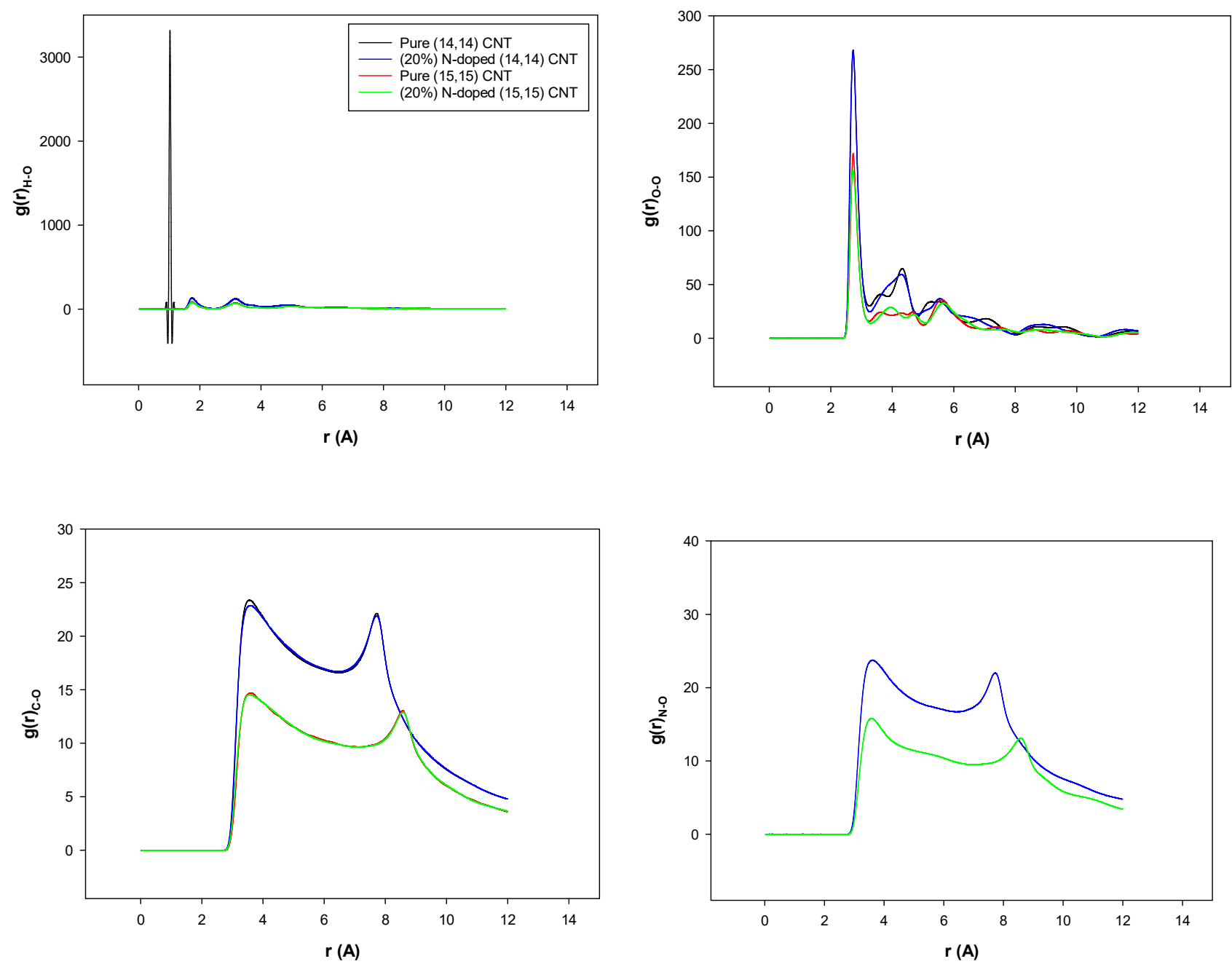

Fig. S13. The different RDFs of the confined molecules in the pure and high N-doped $(14,0)$ and $(15,0)$ CNTs with the random doped atoms distribution. 

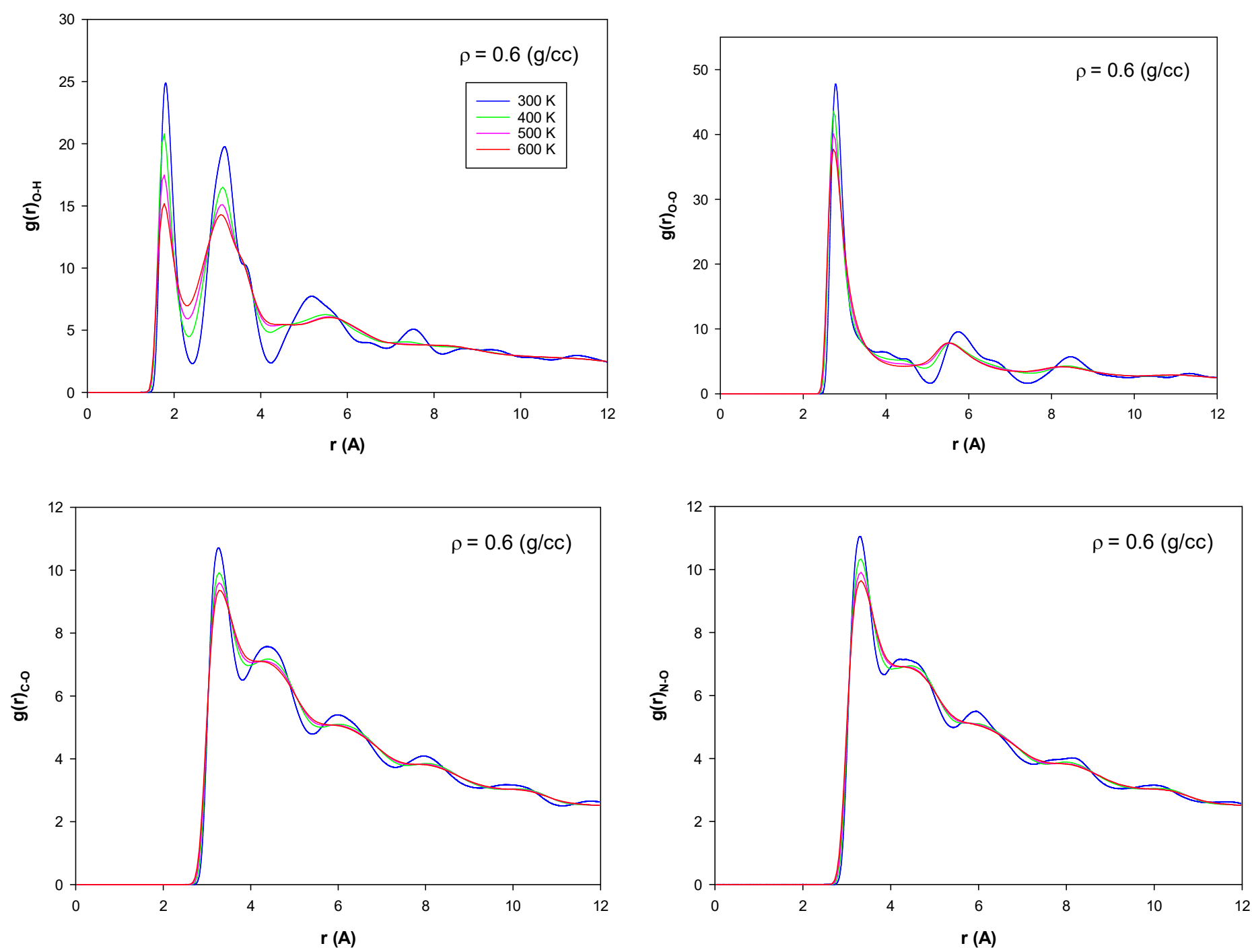

Fig. S14. The different RDFs of the confined molecules in the high N-doped graphene with the random doped atoms distribution with the slit pore of $6(\AA)$ at different temperatures. 

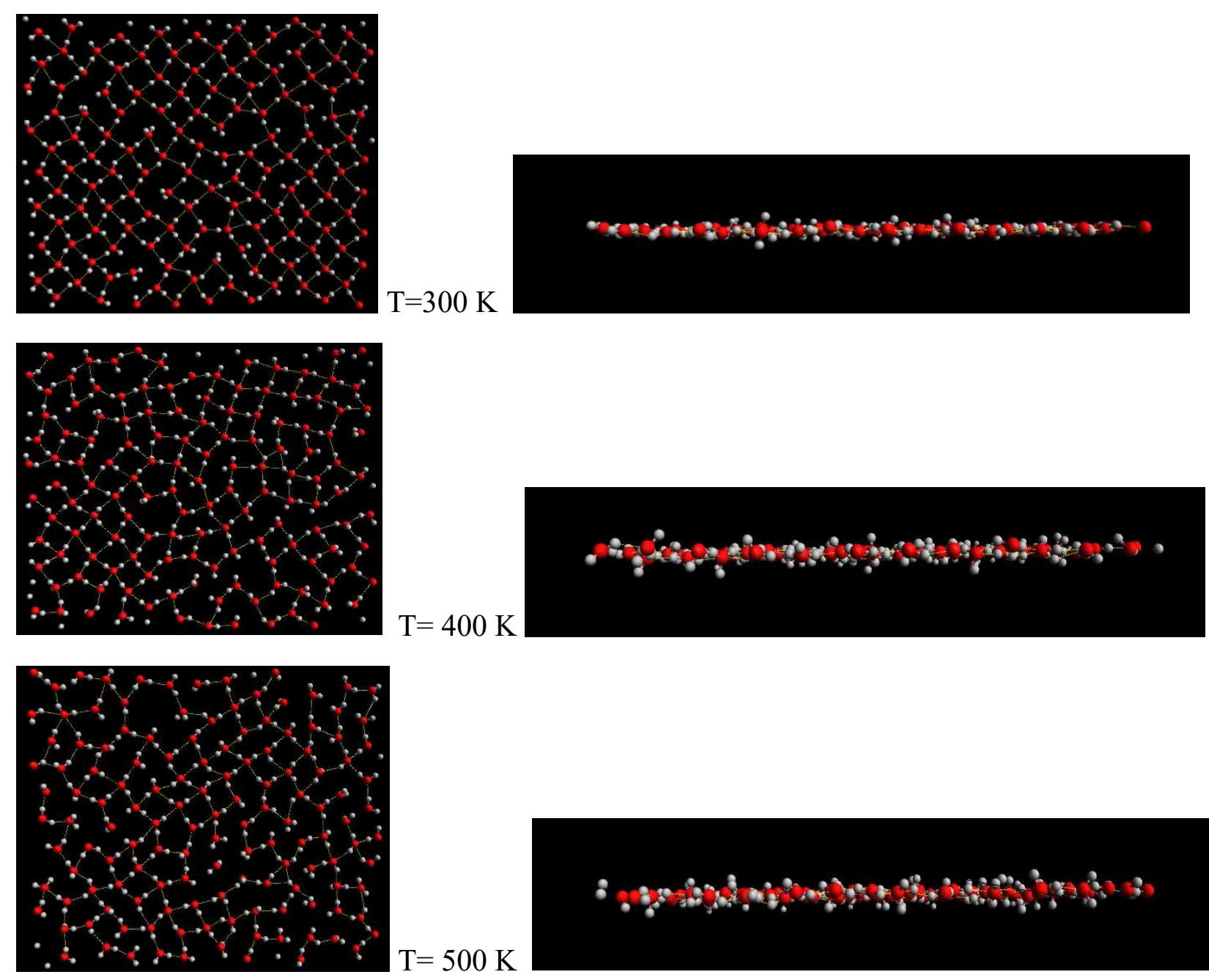

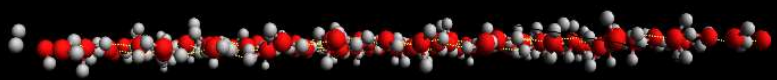

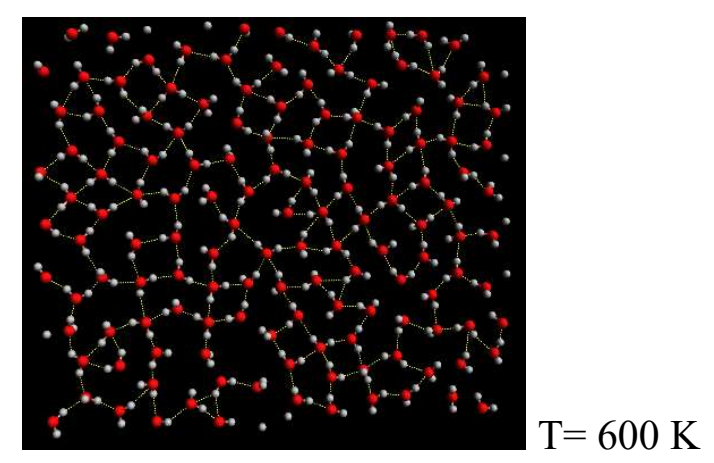

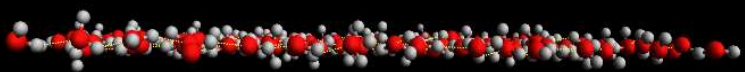

Fig. S15. The snapshots of the confined molecules in the high N-doped graphene with the random doped atoms distribution with the slit pore of $6(\AA)$ at different temperatures. 

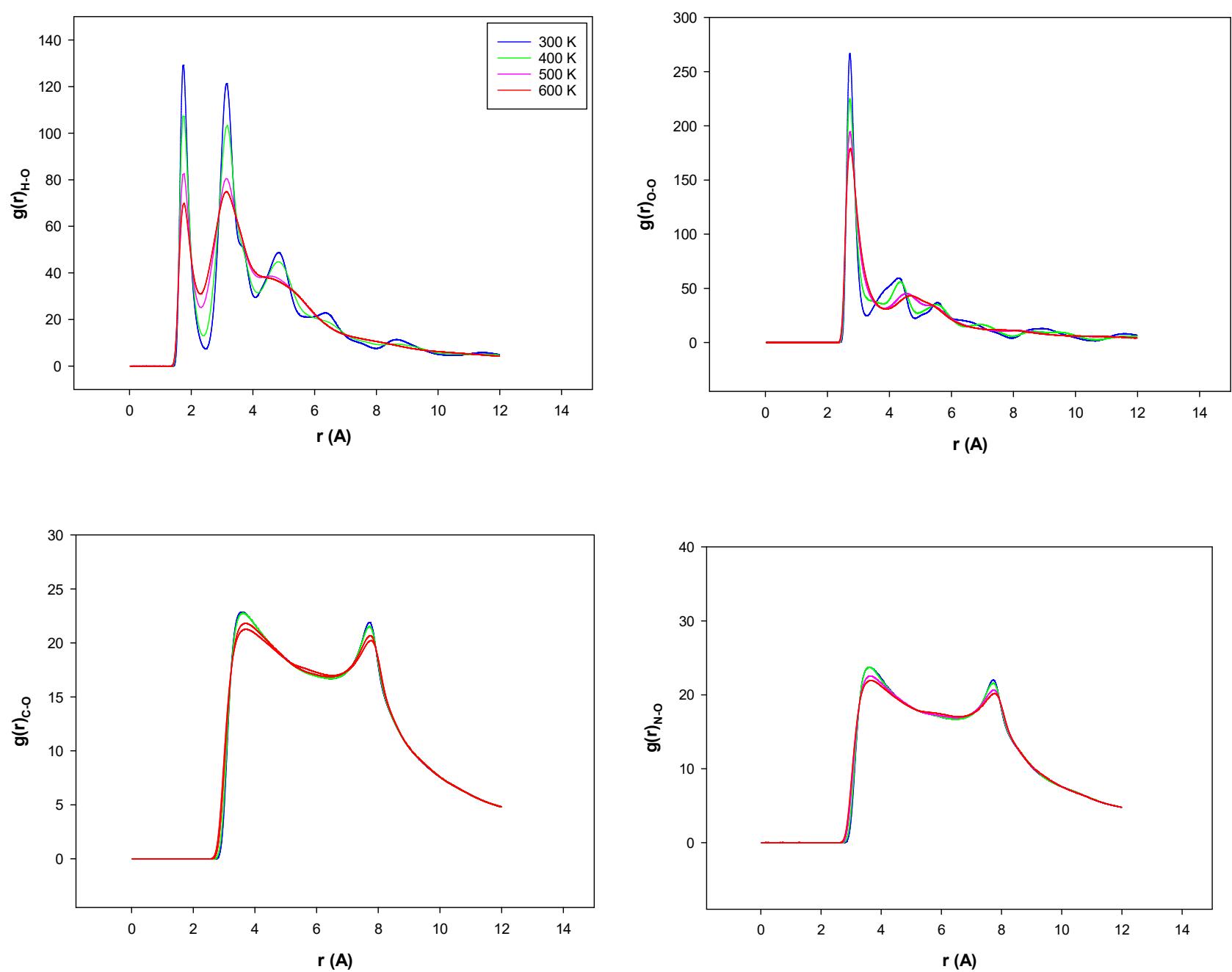

Fig. S16. The different RDFs of the confined molecules in the high N-doped $(14,0)$ CNT with the random doped atoms distribution at different temperatures. 